\title{
Diseminasi Fun Physical Fitness Training untuk Guru Pendidikan Jasmani Olahraga Keseharan (PJOK)
}

\author{
Heryanto Nur Muhammad ${ }^{1 凶}$, Noorce Anita Kumaat ${ }^{2}$, Sri Wicahyani $^{3}$, Lucy Widya Fathir ${ }^{4}$ \\ Universitas Negeri Surabaya, Indonesia ${ }^{1,2,3,4}$ \\ E-mail: heryantomuhammad@unesa.ac.id ${ }^{1}$ noortjeanita@ unesa.ac.id ${ }^{2}$ sriwicahyani@unesa.ac.id $^{3}$, \\ Lucy.19011@mhs.unesa.ac.id ${ }^{4}$
}

\begin{abstract}
Abstrak
Pada masa ini banyak persoalan di lapangan terkait dengan pelaksanaan pembelajaran Pendidikan Jasmani Olahraga Keseharan (PJOK) yang seyogyanya dilakukan dengan praktik langsung dengan tatap muka, namun kita semua harus menyesuaikan dengan kebijakan pemerintah tentang pembelajaran jarak jauh/daring. Dalam kondisi pandemi yang tidak menentu ini dibutuhkan terobosan-terobosan seorang guru dalam upaya menjaga kebugaran siswa agar proses tumbuh kembang siswa serta tingkat kebugaran jasmani mereka terjaga dengan baik. Oleh karena itu S3 Ilmu Keolahragaan Pascasarjana UNESA melalui kegiatan Pengabdian Kepada Masyarakat ini berusaha untuk memberikan kontribusi berupa pemberian keterampilan kepada mitra melalui kegiatan diseminasi Fun Physical Fitness Training. Fun Physical Fitness Training adalah sebuah program aktifitas kebugaran jasmani yang dapat dilakukan oleh siapa saja dari segi usia maupun jenis kelamin. Dengan pemaparan, pendampingan, serta perancangan materi aktifitas fun physical fitness training memberikan wawasan baru bagi guru. Guru dapat secara mandiri menyusun aktifitas-aktifitas pembelajaran aktivitas kebugaran jasmani yang diapliaksikan dalam pembelajaran.
\end{abstract}

Kata kunci: guru, pendikan jasmani olahraga kesehatan, fun physical fitness training

\section{Abstract}

At this time, there are many problems in the field related to the practice of physical education sport \& health learning which usually in direct practice with face to face, but we all have to adjust to the government's policy on distancelonline learning. In this uncertain pandemic condition, breakthroughs from a teacher need to keep up student fitness so that the process of student growth and development and their level of physical fitness are well maintained. Therefore, UNESA Postgraduate Sports Science Doctoral Program through Community Service activities seeks to give in the form of providing skills to partners through Fun Physical Fitness Training dissemination activities. Fun Physical Fitness Training is a program of physical fitness activities that could be done by anyone in terms of age and gender. With exposure, mentoring, and designing fun physical fitness training activity materials, it provides new insights for teachers. Teachers can independently arrange learning activities for physical fitness activities that would applied in learning.

Keywords: teacher, physical education sport \& health, fun physical fitness training

Copyright (c) 2021 Heryanto Nur Muhammad, Noorce Anita Kumaat, Sri Wicahyani, Lucy Widya Fathir

$\triangle$ Corresponding author

Address : Universitas Negeri Surabaya

Email: heryantomuhammad@unesa.ac.id

DOI $\quad:$ https://doi.org/10.31004/abdidas.v2i6.486

ISSN 2721- 9224 (Media Cetak)

ISSN 2721- 9216 (Media Online) 
1339 Diseminasi Fun Physical Fitness Training untuk Guru Pendidikan Jasmani Olahraga Keseharan (PJOK) - Heryanto Nur Muhammad, Noorce Anita Kumaat, Sri Wicahyani, Lucy Widya Fathir

DOI: https://doi.org/10.31004/abdidas.v2i6.486

\section{PENDAHULUAN}

Pendidikan jasmani merupakan bagian integral dari pendidikan. Pendidikan jasmani dilaksanakan dalam rangka mencapai tujuan pendidikan nasional, yang mencakup aspek fisik, intelektual, emosional, sosial, dan moral. Pendidikan jasmani mengandung makna bahwa mata pelajaran ini menggunakan aktivitas jasmani sebagai media untuk mencapai tujuan aktivitas pembelajaran yang direncanakan, yang bertujuan untuk meningkatkan kebugaran jasmani individu (Putra, 2020).

Pendidikan Jasmani Olahraga Kesehatan (PJOK) pada dasarnya merupakan bagian integral dari sistem pendidikan secara keseluruhan, bertujuan untuk mengembangkan aspek kesehatan, kebugaran jasmani, keterampilan berpikir kritis, stabilitas emosional, keterampilan social, penalaran dan tindakan moral melalui aktivitasaktivitas jasmani dan olahraga. Hasi belajar PJOK adalah hasil tertinggi yang diperoleh dari proses pembelajaran PJOK yang berupa perubahan sikap dan penampilan dari individu dengan cara mengamati, menirukan, mencoba dan mendengarkan petunjuk serta pengarahan (Nurul Raodatun Hasanah, I Putu Panca Adi, 2021).

Siswa yang aktif, dalam arti positif, akan dapat mengikuti proses pembelajaran dengan baik sehingga ketercapaian pembelajaran Pendidikan Jasmani yang indikatornya adalah kebugaran tercapai. Begitu juga sebaliknya, bila siswa malas dalam mengikuti pembelajaran, maka indikator yang berupa kebugaran akan sulit tercapai. Ada beberapa kemungkinan yang terjadi, mungkin pembelajaran belum ideal dengan potensi atau kemampuan siswa, mungkin lingkungan yang kurang mendukung untuk proses pembelajaran berlangsung dengan optimal, ataupun mungkin ada masalah lain yang terkait dengan pebelajaran. Faktor eksternal seperti keluarga juga akan berpengaruh, keluarga yang bisa memotivasi anaknya untuk belajar akan memberikan si anak semangat untuk belajar. Memunculkan motivasi kepada siswa dalam mengikuti pembelajaran sangatlah penting, motivasi adalah alasan mereka agar mau melakukan berbagai gerakan yang di ajarkan guru. Disini guru dituntut untuk terampil memberikan motivasi kepada siswa (Baitur Rochman, Nanik Indahwati, 2020).

Upaya untuk mencapai prestasi belajar siswa, dituntut peran guru yang kreatif. Guru yang kreatif menggunakan segala sesuatu yang dimilikinya untuk mengaktualisasikan pembelajaran aktif guna memotivasi siswa, seperti pemikiran, fakta, dan ide-ide atau bahkan kombinasi pemikiran, fakta dan ide-ide. Guru yang kreatif mampu melakukan proses pembelajaran secara efektif dengan menggabungkan berbagai kontekstual instruksional bahan, strategi pengajaran, pembelajaran media dan pengalaman kehidupan nyata. Guru yang kreatif berusaha untuk menyediakan sebanyak mungkin ruang bagi siswa dalam proses pembelajaran (Nopiyanto et al., 2020).

Tingkat kebugaran jasmani dipengaruhi oleh berbagai faktor yang terkadang sulit diamati dan dianalisis. Dari sekian banyak faktor yang berpengaruh terhadap kebugaran jasmani siswa, faktor fisik jika dilakukan dengan terprogram merupakan faktor dominan yang mempengaruhi 
1340 Diseminasi Fun Physical Fitness Training untuk Guru Pendidikan Jasmani Olahraga Keseharan (PJOK) - Heryanto Nur Muhammad, Noorce Anita Kumaat, Sri Wicahyani, Lucy Widya Fathir

DOI: https://doi.org/10.31004/abdidas.v2i6.486

kebugaran maupun kesehatan seseorang. Pola hidup termasuk pola makan serta pengaturan istirahat yang baik merupakan faktor lain yang tidak kalah pentingnya untuk menciptakan kesehatan maupun kebugaran jasmani. Faktorfaktor tersebut saling mempengaruhi satu dengan yang lain (Manik, 2016).

Fun Physical Fitness Training adalah sebuah program aktifitas kebugaran jasmani yang dapat dilakukan oleh siapa saja dari segi usia maupun jenis kelamin. Dengan menggunakan Fun Physical Fitness Training guru tidak perlu harus membeli peralatan baru dengan biaya yang tinggi serta tempat atau lapangan yang luas namun dapat memanfaatkan dari lingkungan yang ada di sekolah dengan menyesuaikan program Fun Physical Fitness Training sesuai tingkat perkembangan siswa.

Fun Fitness Physical Activity disusun utamanya untuk meningkatkan kebugaran jasmani siswa melalu aktifitas yang menyenangkan dengan menggunakan berbagai peralatan yang ada. Intensitas kegiatan disesuaikan dengan kondisi siswa di sekolah. Dengan adanya rancangan yang disusun oleh tim maka guru-guru PJOK tinggal menyesuaikan rancangan aktifitas gerak sesuai dengan kondisi siswa masing-masing. Perlatan yang akan digunakan dalam menyusun rancangan kegiatan Fun Physical Fitness Activity. Berbagai perelatan dan perelngkapan seperti simpai, battle rope, $T R X$, aneka macam dan ukuran bola, dan lain sebagainya digunakan sebagai bagian dalam melaksanakan kegiatan Fun Physical Fitness Training.
Bentuk aktifitas ViPR adalah aktifitas latihan dengan menggunakan alat serupa dengan pipa yaitu ViPR. Pipa ViPR terdiri dari dua jenis. Diameter ukuran sedang memiliki berat $4 \mathrm{~kg}, 6 \mathrm{~kg}$, $8 \mathrm{~kg}$ dan $10 \mathrm{~kg}$. Sementara diameter yang lebih besar dan lebih tinggi memiliki berat $12 \mathrm{~kg}, 16 \mathrm{~kg}$, $20 \mathrm{~kg}, 24 \mathrm{~kg}$ dan $26 \mathrm{~kg}$. Berat maksimal biasanya diperuntukkan bagi atlet dan kalangan fitnes profesional. ViPR dapat dimodifikasi dengan berbagai peralatan sederhana, misalnya pipa peralon yang didesain serupa dengan ViPR asli, baik dari ukuran maupun beratnya dapat disesuaikan dengna kebutuhan. ViPR sendiri merupakan singkatan dari Vitality, Power \& Reconditionin yang berfungsi meningkatkan kemampuan tubuh secara keseluruhan, untuk beraktivitas dengan lebih optimal.

Bentuk aktifitas TRX (Total Body Resistance Exercise) adalah latihan kekuatan seluruh tubuh yang memanfaatkan berat badan sendiri alih-alih mengandalkan mesin atau dumbel dan alat weigh training lainnya. Alat dasar yang digunakan dalam olahraga TRX adalah sebuah tali suspensi atau suspension straps. Tali ini bisa kamu beli sendiri untuk latihan di rumah, atau menggunakan fasilitas yang ada di gym. Melakukan aktifitas TRX dengan suspension straps dapat dilakukan kapan saja dan dimana saja serta tidak banyak membutuhkan persiapan alat karenan bersifat sederhana. Latihan TRX tidak terlalu menekan persendian dan memiliki risiko cedera yang rendah sehingga memungkinkan kamu untuk berlatih sekeras mungkin tanpa memperparah cedera yang sudah ada sebelumnya. 
1341 Diseminasi Fun Physical Fitness Training untuk Guru Pendidikan Jasmani Olahraga Keseharan (PJOK) - Heryanto Nur Muhammad, Noorce Anita Kumaat, Sri Wicahyani, Lucy Widya Fathir

DOI: https://doi.org/10.31004/abdidas.v2i6.486

Bentuk aktifitas Bosu ball merupakan latihan keseimbangan tubuh dengang menggunakan bosu ball. Bosu ball merupakan bola berbentuk setengah lingkaran yang terbuat dari karet plastik atau material sejenisnya. Materialnya yang sangat elastis ini membuatnya nyaman digunakan ketika melakukan beragam aktifitas olahraga. Olahraga menggunakan bosu ball, tidak hanya baik untuk menjaga keseimbangan tubuh, namun juga mampu mengencangkan pergelangan tangan, paha, hingga kaki. Karena semua tumpuan terdapat pada area tersebut, olahraga ini menitikberatkan pada kekuatan tubuh sendiri.

Bentuk aktifitas Battle rope merupakan latihan-latihan dengan menggunakan battle rope. Melakukan latihan battle rope dapat melibatkan banyak otot yang akan terlatih, seperti otot punggung, tricep, bicep dan otot lengan dengan berbagai variasi gerakan seperti double arm wave, single arm wave, hip toss, arm circles, power slam dan masih banyak lagi dengan tambahan variasi langkah/pergeseran badan.

Power slam adalah olahraga battle rope yang dapat dilakukan dengan berdiri dengan kaki terbuka selebar bahu dan posisi tubuh agak jongkok. Pegang sisi tali di masing-masing tangan. Kemudian, turunkan tali ke sisi tubuh dengan lengan terentang. Turunkan posisi jongkok dan kencangkan otot inti Anda. Setelah itu, melompat tinggi ke udara sambil mengangkat kedua tangan ke atas. Saat mendarat ke posisi squat, hentakkan tali ke lantai dengan gerakan gelombang. Ulangi gerakan 30 detik, istirahat selama 30 detik dan lakukan 3-4 set.
Mitra dari S3 Ilmu Keolahragaan Pascasarjana UNESA yaitu guru-guru Pendidikan Jasmani Olahraga dan Kesehatan (PJOK) yang tergabung dalam Musyawarah Guru Mata Pelajaran (MGMP) dan Kelompok Kerja Guru (KKG) PJOK yang berasal dari 20 Kecamatan seKabupaten Nganjuk. Pada masa ini banyak persoalan di lapangan terkait dengan pelaksanaan pembelajaran PJOK yang seyogyanya dilakukan secara praktik langsung dengan tatap muka, namun kita semua harus menyesuaikan dengan kebijakan pemerintah tentang pembelajaran jarak jauh/daring. Dalam kondisi pandemi yang tidak menentu ini dibutuhkan terobosan-terobosan seorang guru dalam upaya menjaga kebugaran siswa agar proses tumbuh kembang siswa serta tingkat kebugaran jasmani mereka terjaga dengan baik. Oleh karena itu S3 Ilmu Keolahragaan Pascasarjana UNESA melalui kegiatan Pengabdian Kepada Masyarakat ini berusaha untuk memberikan kontribusi berupa pemberian keterampilan kepada mitra melaluai kegiatan diseminasi Fun Physical Fitness Training.

\section{METODE}

Metode pendekatan yang digunakan dalam kegiatan Pengabdian Kepada Masyarakat ini adalah melalui workshop, pelatihan, pendampingan perancangan Fun Physical Fitness dan praktikum hasil kegiatan yang diselenggarakan secara langsung/offline.

Fun Physical Fitness Training yang akan disampaikan mencakup gerakan-gerakan yang dirancang sedemikian rupa untuk melatihkan kebugaran jasmani siswa dengan menggunakan 
1342 Diseminasi Fun Physical Fitness Training untuk Guru Pendidikan Jasmani Olahraga Keseharan (PJOK) - Heryanto Nur Muhammad, Noorce Anita Kumaat, Sri Wicahyani, Lucy Widya Fathir

DOI: https://doi.org/10.31004/abdidas.v2i6.486

alat berupa TRX Suspension Training, Bosu Ball, Kettleball, dan Vipr.

Partisipasi dalam hal ini adalah mitra yaitu guru-guru PJOK yang tergabung dalam Kelompok Kerja Guru (KKG) Kabupaten Nganjuk akan mengikuti kegiatan mulai dari perencanaan, penyusunan dan perancangan serta mengaplikasikan Fun Physical Fitness yang dilakukan sesuai dengan jadwal yang ditetapkan. Para guru akan dibuat kelompok-kelompok untuk dapat bekerja menyusun rancangan aktifitas.

Evaluasi pelaksanaan program akan dilakukan pada saat kegiatan berangsung untuk mengetahui tingkat partisipasi peserta dan untuk mendapatkan umpan balik terkait kegiatan yang dilakukan. Keberlanjutan program masih akan dapat dipantau melalui group whatssapp peserta yang dibuat untuk kepentingan kegiatan diseminasi ini.

\section{HASIL DAN PEMBAHASAN}

Universitas Negeri Surabaya (UNESA) dengan visi "Unggul dalam Pendidikan dan Kukuh dalam Keilmuan", berkomitmen untuk melaksanakan kegiatan Pengabdian Kepada Masyarakat (PKM) dalam rangka berpartisipasi memecahkan persoalan-persoalan pendidikan terutama di lingkungan Universitas Negeri Surabaya dan sekitarnya. Salah satu bentuk kegiatan pengabdian tersebut adalah dengan terjun langsung ke sasaran yaitu mitra dari Universitas Negeri Surabaya (UNESA) untuk meningkatkan pengetahuan dan keterampilan mitra.

Pada tahun 2021 ini, Pascasarjana Universitas Negeri Surabaya mengadakan kegiatan pengabdian secara terpadu yaitu di Kabupaten Nganjuk pada hari Sabtu, 2-5 Oktober 2021 yang diikuti oleh tim PKM Pascasarjana salah satunya adalah S3 Ilmu Keolahragaan. Pada kegiatan diseminasi oleh S3 Ilmu Keolahragaan didapatkan data-data tentang realita di lapangan berkaitan dengan tema diseminasi. Berikut ini adalah data tentang pengetahuan awal tentang alat Fun Physical Fitness Training guru PJOK.

Tabel 1. Persentase Pengetahuan Alat

\begin{tabular}{ccccc}
\hline No & $\begin{array}{c}\text { Nama } \\
\text { Alat }\end{array}$ & Tahu & $\begin{array}{c}\text { Tidak } \\
\text { Tahu }\end{array}$ & Jumlah \\
\hline 1 & ViPR & $22 \%$ & $78 \%$ & $100 \%$ \\
\hline 2 & TRX & $22 \%$ & $78 \%$ & $100 \%$ \\
\hline 3 & $\begin{array}{c}\text { Bosu } \\
\text { ball }\end{array}$ & $11 \%$ & $89 \%$ & $100 \%$ \\
\hline 4 & $\begin{array}{c}\text { Battle } \\
\text { rope }\end{array}$ & $22 \%$ & $78 \%$ & $100 \%$ \\
\hline
\end{tabular}

Pemahaman alat untuk media atau sarana pembelajaran sangat penting bagi guru. Untuk dapat melakukan aktivitas olahraga dengan baik di perlukan alat atau sarana yang mendukung kegiatan tersebut. Sarana olahraga adalah suatu alat atau bahan yang dapat di gunakan dan di manfaatkan dalam pelaksanaan kegiatan olahraga atau pendidikan jasmani. Sebagai contoh sarana olahraga atau pendidikan jasmani adalah bola yang di pakai dalam permaianan sepak bola, tongkat yang di pakai pada nomor lari estapet dalam olahraga atletik dan lain-lain. Prasarana adalah segala sesuatu yang merupakan penunjang terselenggaranya sesuatu kegiatan atau proses belajar mengajar pendidikan jasmani, sarana ini diperlukan disegala kegiatan pembelajaran khususnya pelajaran yang memiliki banyak 
1343 Diseminasi Fun Physical Fitness Training untuk Guru Pendidikan Jasmani Olahraga Keseharan (PJOK) - Heryanto Nur Muhammad, Noorce Anita Kumaat, Sri Wicahyani, Lucy Widya Fathir

DOI: https://doi.org/10.31004/abdidas.v2i6.486

aktivitas seperti pendidikan jasmani (Tawardi, Sukardi Putra, 2015).

Pengetahuan tentang penggunaan alat dalam Fun Physical Fitness Training guru PJOK adalah sebagai berikut.

Tabel 2. Persentase Penggunaan Alat

\begin{tabular}{ccccc}
\hline No & $\begin{array}{c}\text { Nama } \\
\text { Alat }\end{array}$ & $\begin{array}{c}\text { Pernah } \\
\text { mencoba }\end{array}$ & $\begin{array}{c}\text { Belum } \\
\text { pernah } \\
\text { Mencoba }\end{array}$ & Jumlah \\
\hline 1 & ViPR & $6 \%$ & $94 \%$ & $100 \%$ \\
\hline 2 & TRX & $6 \%$ & $94 \%$ & $100 \%$ \\
\hline 3 & $\begin{array}{c}\text { Bosu } \\
\text { ball }\end{array}$ & $6 \%$ & $94 \%$ & $100 \%$ \\
\hline 4 & $\begin{array}{c}\text { Battle } \\
\text { rope }\end{array}$ & $6 \%$ & $94 \%$ & $100 \%$ \\
\hline
\end{tabular}

Pemanfaatan berbagai alat dan sarana dapat meningkatkan motivasi belajar siswa. Siswa akan merasa tertarik dan ingin tahu serta ingin mencoba alat tersebut terutama alat yang belum pernah mereka lihat atau coba sebelumnya. Dan muncul adanya ketertarikan rekan lain serta keterlibatan aktivitas menggunakan alat tersebut.

Rerata penilaian terhadap bentuk aktifitas Fun Physical Fitness Training Training guru PJOK adalah sebagai berikut.

Tabel 3. Rerata Penilaian terhadap Bentuk Aktifitas Fun Physical Fitness Training

\begin{tabular}{lll}
\hline No & Nama Alat & Rerata Skor \\
\hline 1 & $\begin{array}{l}\text { Bentuk aktifitas dengan } \\
\text { alat ViPR }\end{array}$ & 4,11 \\
\hline 2 & $\begin{array}{l}\text { Bentuk aktifitas dengan } \\
\text { alat TRX }\end{array}$ & 4,00 \\
\hline 3 & $\begin{array}{l}\text { Bentuk aktifitas dengan } \\
\text { alat Bosu ball }\end{array}$ & 4,17 \\
\hline 4 & $\begin{array}{l}\text { Bentuk aktifitas dengan } \\
\text { alat Battle rope }\end{array}$ & 4,28 \\
\hline Rata-rata & 4,13 \\
\hline *Keterangan: Rentang nilai 1-5 &
\end{tabular}

Penilaian rata-rata tentang penyajian bentuk aktifitas Fun Physical Fitness Training Training dengan skor 4,14 masuk pada kategori tinggi.

Rerata penilaian terhadap manfaat aktifitas Fun Physical Fitness Training Training guru PJOK adalah sebagai berikut.

Tabel 4. Rerata Penilaian terhadap Manfaat Aktifitas Fun Physical Fitness Training

\begin{tabular}{lll}
\hline No & Nama Alat & Rerata Skor \\
\hline 1 & $\begin{array}{l}\text { Manfaat aktifitas } \\
\text { dengan alat ViPR }\end{array}$ & 4,22 \\
\hline 2 & $\begin{array}{l}\text { Manfaat aktifitas } \\
\text { dengan alat TRX }\end{array}$ & 4,22 \\
\hline 3 & $\begin{array}{l}\text { Manfaat aktifitas } \\
\text { dengan alat Bosu ball }\end{array}$ & 4,28 \\
\hline 4 & $\begin{array}{l}\text { Manfaat aktifitas } \\
\text { dengan alat Battle } \\
\text { rope }\end{array}$ \\
\hline Rata-rata & 4,28 \\
\hline
\end{tabular}

*Keterangan: Rentang nilai 1-5

Penilaian rata-rata tentang penyajian manfaat aktifitas Fun Physical Fitness Training Training dengan skor 4,25 masuk pada kategori tinggi.

Hasil wawancara tentang pemberian materi aktifitas Fun Physical Fitness Training didapatkan beberapa pernyataan secara umum subyek penelitian yaitu (1) menambah pengetahuan dan ilmu sangat bermanfaat, (2) materinya sangat mendukung untuk kegiatan pembelajaran di sekolah, (3) senang karena mendapat ilmu baru yang sangat bermanfaat, (4) sangat bermanfaat untuk peserta, (5) penyampaian menarik mudah dipahami, (5) menyenangkan, (6) menarik untuk di terapkan pada murid di sekolah, (7) Fun Physical Fitness Training Sangat perlu di ajarkan pada anak 
1344 Diseminasi Fun Physical Fitness Training untuk Guru Pendidikan Jasmani Olahraga Keseharan (PJOK) - Heryanto Nur Muhammad, Noorce Anita Kumaat, Sri Wicahyani, Lucy Widya Fathir

DOI: https://doi.org/10.31004/abdidas.v2i6.486

didik di usia sekolah dasar, (8) merasa antusias, (9) cukup menarik dan menyenangkan serta memberi tambahan pengetahuan tentang fitness training, (10) sangat mengesankan, menambah pengetahuan saya tentang Fun Physical Fitness bagi siswa, (11) senang mendapat ilmu baru.

\section{SIMPULAN}

Pemaparan, pendampingan, serta perancangan materi aktifitas Fun Physical Fitness training dalam ekgiatan diseminasi memberikan wawasan baru bagi guru. Guru dapat secara mandiri menyusun aktifitas-aktifitas pembelajaran pada materi aktivitas kebugaran jasmani yang dapat diaplikasikan dalam pembelajaran PJOK untuk meningkatkan kebugaran jasmani siswa dengan memperhatikan individual differences pada diri masing-masing siswa dan dapat dijalankan dirumah dengan pengamatan oleh guru.

\section{UCAPAN TERIMAKASIH}

Ucapan terimakasih kami ucapkan kepada mitra yaitu MGMP Pendidikan Jasmani Olahraga Kesehatan (PJOK) Kabupaten Nganjuk atas partisipasi dan kerjasamanya.

\section{DAFTAR PUSTAKA}

De Porter, Bobbi Dan Hernacki, Mike. 1992. Quantum Learning. Membiasakan Belajar Nyaman Dan Menyenangkan. Terjemahan Oleh Alwiyah Abdurrahman. Bandung: Penerbit Kaifa.

Baitur Rochman, Nanik Indahwati, A. P. (2020). Identifikasi Keterlaksanaan Pembelajaran PJOK Tingkat SMP Di Masa Pandemi Covid 19 Se-Kabupaten Sidoarjo. Jurnal Ilmiah ..., 6(1), 257-265. http://ejournal.mandalanursa.org/index.php/JI

\section{ME/article/view/1343}

Manik, S. (2016). Etika dan permasalahan dalam pendidikan jasmani dan olahraga di Indonesia. Jurnal Ilmu Keolahragaan, 15(2), 71-88.

https://jurnal.unimed.ac.id/2012/index.php/JI K/article/view/6141

Nopiyanto, Y. E., Raibowo, S., Suryatama, R. yaya, \& Ibrahim. (2020). Hambatan Guru Penjas Generasi 80-an dalam Pembelajaran Daring di Tengah Pandemi Covid-19. Jurnal Sporta Saintika, 5(2), 139-148. http://www.elsevier.com/locate/scp

Nurul Raodatun Hasanah, I Putu Panca Adi, I. G. S. (2021). Survey Pelaksaan Pembelajaran Pjok Secara Daring Pada Masa Pandemi Covid-19. Jurnal Kejaora: Jurnal Kesehatan Jasmani Dan Olahraga, 6(1), 189-196. https://doi.org/https://doi.org/10.36526/kejao ra.v6i1.1295

Putra, A. N. (2020). Implementasi Pembelajaran Pjok Pada Masa Pandemi Covid-19 Di Sd Negeri Se-Kecamatan Lendah Kabupaten Kulon Progo daerah Istimewa Yogyakarta. 1, 70.

Tawardi, Sukardi Putra, Z. (2015). Evaluasi Sarana Dan Prasarana Penjasorkes Pada Sdlb Sekabupaten Bener Meriah Tahun Ajaran 2012/2013. Urnal Ilmiah Mahasiswa Pendidikan Jasmani, Kesehatan Dan Rekreasi, 1(20), 133-140. 